NEUROSCIENCE

\section{Bee exploration mechanism}

Honeybees orient using similar molecular pathways to many vertebrates.

Gene Robinson and Claudia Lutz at the University of Illinois at Urbana-Champaign identified a protein in honeybees (Apis mellifera) similar to the transcription factor Egr1, which is expressed in the brains of vertebrates such as rodents during the exploration of new environments.

Egr was upregulated only in regions of the bee brain called mushroom bodies - which integrate sensory input and process memories - and only as the bees learned to orient in unfamiliar surroundings. This was true of both young bees that had previously never left the hive and experienced foragers placed in a new environment. The results demonstrate the deep evolutionary conservation of Egr-related molecular pathways in experiencedependent learning, say the authors.

J. Exp. Biol. 216, 2031-2038 (2013)

\section{GENOMICS}

\section{Irish-famine pathogen decoded}

Researchers have sequenced the genome of the microorganism that devastated the Irish potato crop in the 1840 s - the first time the genome of a historical plant pathogen has been decoded.

Kentaro Yoshida at the Sainsbury Laboratory in Norwich, UK, and his colleagues identified the strain of Phytophthora infestans, which causes potato late blight, from nineteenth-century

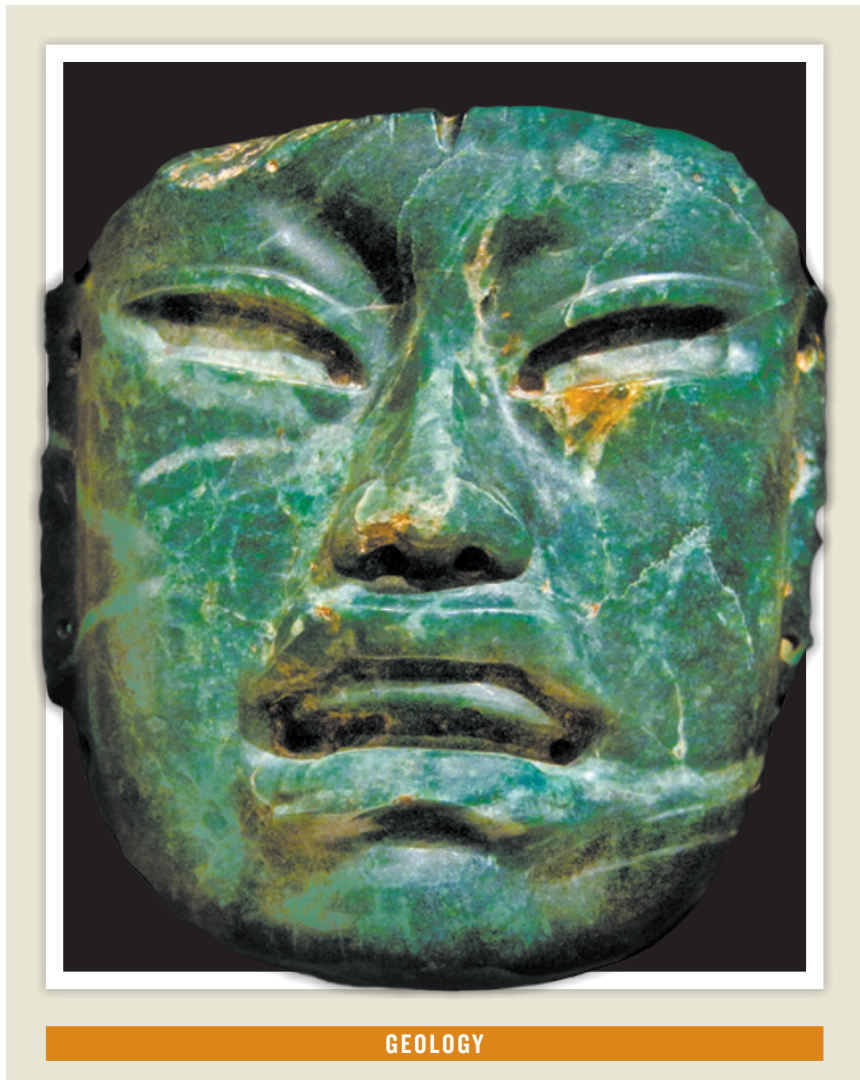

\section{Gemstones from the deep}

The precious stones jade and ruby can be used to identify the sites of ancient collisions of tectonic plates.

Robert Stern at the University of Texas at Dallas and his colleagues suggest that these two substances could be called "plate tectonic gemstones". Jadeitite, a type of jade, forms where one tectonic plate plunges beneath another. Fluids that rise from the diving slab of oceanic crust condense to form the gemstone (pictured in an Olmec mask from southern Mexico - the site of one such subduction zone). By contrast, ruby forms where continental crust rich in aluminium collides, as in Southeast Asia.

These stones should be recognized not only for their beauty but also for what they reveal about their tectonic setting, the authors say.

Geology http://dx.doi.org/10.1130/G34204.1 (2013) dried leaves. The researchers sequenced DNA from 11 historical specimens, which had been stored in herbaria, and from 15 modern strains of $P$. infestans. The famine strain was closely related to another strain that is still prevalent around the world, and the researchers suggest that the two strains diverged in the early 1800 s. The famine strain may now be extinct, the authors say.

eLIFE http://dx.doi.org/10.7554/ elife.00731 (2013)

For a longer story on this research see go.nature.com/qg2aov
HUMAN EVOLUTION

\section{Footprints reveal hominin size}

Fossil footprints indicate that hominins were already as large as modern humans by 1.52 million years ago.

Undamaged fossil skeletons from that time are rare, and so determining characteristics such as the size and walking speed of human ancestors has been challenging. Brian Richmond and Heather Dingwall at George Washington University in Washington DC and their colleagues measured foot size and stride length from fossil footprints of seven individuals - which were probably Homo erectus or Paranthropus boiseidiscovered in northern Kenya. To translate these measurements into physical attributes such as stature, body mass and walking speed, the researchers studied the relationship between body dimension and gait in habitually barefoot modern adults from Kenya. The authors were then able to infer that the size of these hominins was comparable to that of modern humans.

J. Hum. Evol. 64, 556-568 (2013)

\section{CHEMISTRY}

\section{Metabolites, cell by cell}

Single-cell measurements are revealing how individual yeast cells react to environmental and genetic challenges.

Advances in mass spectrometry, which identifies individual compounds in complex mixtures, have given researchers the chance to compose cell-by-cell portraits of metabolism. Renato 
Zenobi at the Swiss Federal Institute of Technology in Zurich and his colleagues used the approach to profile how baker's yeast (Saccharomyces cerevisiae) responds to 2-deoxyglucose, which blocks the breakdown of glucose, and a genetic mutation known to mimic the effects of this substance.

The authors found that the single-cell approach allowed them to identify subpopulations of cells. For example, some cells accumulated high levels of a metabolite called F16BP, whereas others did not. This observation would have been missed if the analyses were carried out on a population of cells.

Proc. Natl Acad. Sci. USA http://dx.doi.org/10.1073/ pnas.1209302110 (2013)

\section{Artificial insect eyes}

A multi-lens artificial eye that can adapt to light mimics the

岸 eyes of arthropods such as the fruitfly.

Whereas human eyes and most cameras - use a single lens, the compound eyes of arthropods have hundreds of light-sensing structures that are arranged in a hemisphere. Dario Floreano at the Swiss Federal Institute of Technology in Lausanne and his colleagues have created an artificial compound eye by stacking microlenses on top of silicon photodetectors and printed circuit boards, cutting the components so that they can curve around into a half cylinder. The artificial eye gives a wide field of view, but the prototype (pictured with an arthropod model for

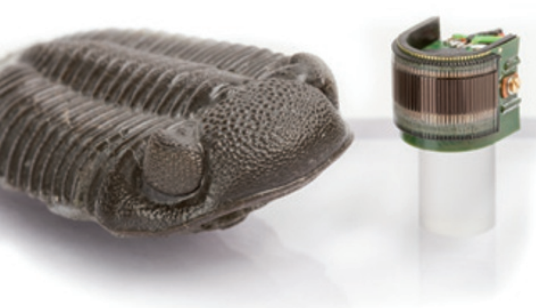

scale) weighs 1.75 grams and is about the size of a crab's eye. Compound eyes made from lenses embedded in soft polymers have already been reported, but the integrated circuitry in this new eye has the advantage of fast and programmable image processing, allowing it to sense and adapt to changes in lighting conditions.

Proc. Natl Acad. Sci. USA

http://dx.doi.org/10.1073/

pnas.1219068110 (2013)

\section{PALAEONTOLOGY}

\section{Fossil arthropod with scissor hands}

A marine arthropod with long, three-pronged claws has been described from 505-million-year-old fossils.

David Legg at Imperial College London named the creature Kootenichela deppi after Kootenay National Park in British Columbia, Canada, where the fossils were found; chela, the Latin for claw; and Johnny Depp, the actor who played the blade-fingered Edward Scissorhands in the film of the same name. Fossils have been given similarly whimsical names before; for example, one arthropod was called Han solo.

\section{K. deppi (pictured)} was described on the basis of three specimens. Legg puts the sharp-handed beast in the arthropod class Megacheira (great appendage). He also reassigns Worthenella cambria, which was originally described in 1911 as a segmented worm, as a sister megacheiran.

J. Paleontol. 87, 493-501 (2013)

\section{ZOOLOGY \\ Sea and sky comes at a cost}

The energetic cost of using wings for both flying and swimming probably forced penguins out of the air.

Kyle Elliot at the University

COMMUNITY CHOICE

The most viewed papers in science

\section{Nuclear power saves lives}

\section{HIGHLY READ \\ on pubs.acs.org \\ 20 April-20 May}

Nuclear power might have prevented almost two million air-pollution-related deaths around the world, an analysis of historical data suggests.

Former NASA scientist James Hansen, who left the agency in early April to devote his time to climate activism, and Pushker Kharecha at the NASA Goddard Institute for Space Studies in New York estimate that nuclear power has prevented some 1.84 million deaths that would have occurred had that power been generated by burning fossil fuels. This equates to 370 times more lives saved than have been lost to radiation poisoning or occupational accidents in nuclear power plants over the past 40 years or so. In addition, the power generated by the technology has prevented 64 gigatonnes of carbon-dioxide-equivalent greenhouse-gas emissions, which would have accompanied the burning of fossil fuels, from entering the atmosphere.

Environ. Sci. Technol. 47, 4889-4895 (2013) of Manitoba in

Winnipeg, Canada, Robert Ricklefs at the University of Missouri in St Louis and their colleagues attached data recorders to two types of diving bird - 41 thickbilled murres (Uria lomvia) and 22 pelagic cormorants (Phalacrocorax pelagicus). Then the researchers injected the birds with isotopically labelled water, which allowed them to estimate the creatures' metabolic rates. The authors used data from the recorders on the depth and temperature of dives and length of flights to model the energy costs of these activities.

Both birds had the highest recorded flight costs seen in vertebrates, and higher diving costs than penguins. This suggests that adaptations for diving may compromise flight, and that adaptation of wings for optimal diving make flight impossible.

Proc. Natl Acad. Sci. USA http://dx.doi.org/10.1073/ pnas. 1304838110 (2013)

\section{CONDENSED-MATTER PHYSICS}

\section{Neatly trapped exotic matter}

An exotic form of matter, in which many atoms share a single quantum-mechanical state, has been trapped in a new and useful way.

Bose-Einstein condensates are usually created in traps bounded by an electric field that varies gradually across the sample, producing a 'fuzzy' edge rather than a sharp cut-off. Now Alexander Gaunt and his team at the University of Cambridge, UK, have transferred a volume of matter created in this way to a cylindrical box with welldefined 'walls' of laser light. The technique should enable experiments on exotic matter that conform more rigorously to theoretical descriptions. It could also be adapted to make traps of different shapes, the authors say.

Phys. Rev. Lett. 110, 200406 (2013)

\section{ONATURE.COM}

For the latest research published by Naturevisit:

www.nature.com/latestresearch 